\title{
THE EFFECT OF COPROCESSED SUPERDISINTEGRANTS RATIO (CROSPOVIDONE-SODIUM STARCH GLYCOLATE) TO THE PHYSICOCHEMICAL CHARACTERISTICS OF ATENOLOL ORALLY DISINTEGRATING TABLETS
}

\author{
NANI PARFATI, KARINA CITRA RANI*, MEILANY \\ Department of Pharmaceutics, UBAYA College of Pharmacy, University of Surabaya, Kalirungkut, Surabaya 60293, East Java, Indonesia. \\ Email: karinacitrarani@staff.ubaya.ac.id
}

Received: 10 October 2017, Revised and Accepted: 20 September 2017

ABSTRACT

Objective: The objective of this study was to evaluate the effect of coprocessed superdisintegrants (crospovidone-sodium starch glycolate) ratio 1:1; 1:2; and 1:3 to the physicochemical characteristics of atenolol orally disintegrating tablets.

Methods: Orally disintegrating tablets of atenolol were prepared by direct compression method. There were three formulas which using three different ratios of coprocessed superdisintegrants (crospovidone-sodium starch glycolate). The ratio of coprocessed superdisintegrants were, 1:1 (formula 1); 1:2 (formula 2); and 1:3 (formula 3). Evaluation of the formulas was conducted before compression (pre-compression evaluation) and after compression (post-compression evaluation).

Results: The results of pre-compression evaluation showed that all the formulas have good flowability and excellent angle of repose. The results of post-compression evaluation showed that all the formulas met the specification of orally disintegrating tablets. The different ratio of coprocessed crospovidone-sodium starch glycolate $(1: 1 ; 1: 2$; and $1: 3)$ caused significant differences in tablet dispersion time (p<0.05). Dissolution test showed that all the formulas met the specification of dissolution from atenolol tablet (not $<85 \%$ of atenolol was dissolved in 30 min). Formula 1 showed the

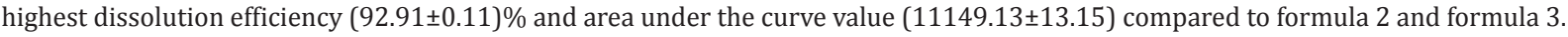

Conclusion: The results from this study showed that coprocessed superdisintegrants (crospovidone-sodium starch glycolate) ratio affect the physicochemical characteristics of atenolol orally disintegrating tablet. Based on pre-compression evaluation and post-compression evaluation, formula 1 was the best formula.

Keyword: Coprocessed, Superdisintegrants, Atenolol, Orally disintegrating tablets.

(C) 2018 The Authors. Published by Innovare Academic Sciences Pvt Ltd. This is an open access article under the CC BY license (http://creativecommons. org/licenses/by/4. 0/) DOI: http://dx.doi.org/10.22159/ajpcr.2018.v11i2.23010

\section{INTRODUCTION}

Hypertension is the most common cardiovascular disease, its prevalence increases with advancing age. Hypertension is the principal cause of stroke, moreover, hypertension is a major risk factor for coronary artery disease and its complications. Atenolol is a competitive beta (1) -selective adrenergic antagonists and has been widely used in hypertension therapy [1]. Administration of conventional tablets of atenolol has been reported to exhibit poor patient compliance in geriatric patients. It is due to physiological and neurological changing which has been suffered by geriatric patients, such as difficulty of swallowing (dysphagia), hand tremors, and deficiency of memory [2].

Atenolol has a low solubility characteristic in water and gastric fluid [3]. For poorly soluble orally administered drugs, the rate of absorption is often controlled by the rate of dissolution. The rate of dissolution can be increased by increasing the surface area of available drug by various methods (micronation, complexation, solid dispersion, etc.). Another prerequisite for the fast dissolution may be the disintegration time of tablets. The faster disintegration of tablets delivers a fine suspension of drug particles, and thus, faster onset of dissolution and greater dissolution of the drug will be attained [4].

Based on these facts, the development of atenolol orally disintegrating tablets is the solution to improve the effectiveness of the drug and patient compliance in hypertension therapy. Orally disintegrating tablets disintegrate rapidly in the oral cavity so that the drug will be imbibed from the oral cavity, throat, and esophagus when the saliva move toward to the stomach [5]. Orally disintegrating tablets are novel types of tablets that disintegrate/dissolve/disperse in saliva within few seconds. This result in a rapid onset of action and greater bioavailability of the drug than those observed from a conventional tablet dosage form [6]. US FDA stated that orally disintegrating tablet is a tablet which disintegrates in oral cavity <30 s [7]. Orally disintegrating tablet also can minimize or eliminate the bitter taste of the drug or patient inconvenience [8].

In recent year drug formulation scientist has recognized that singlecomponent excipients do not always provide the desired performance to allow certain active pharmaceutical ingredients to be formulated or manufactured adequately. Hence, there is a need to have excipient with multiple characteristics built into them such as better flow, low moisture sensitivity, superior compressibility, and rapid disintegration ability [9]. One such approach for improving the functionality of excipients is coprocessing of two or more excipients. Coprocessing is based on the novel concept of two or more excipients interacting at the sub particle level [8]. The objective of preparing coprocessed excipient is to provide a synergy of functionality improvement as well as masking the undesirable properties of the individual component. Coprocessing excipients have superior properties compared with physical mixtures of components or individual components [9].

Drug delivery technologies such as orally disintegrating tablets need fast disintegrate with very good mouth feeling and physical characteristics [10]. Superdisintegrants are the class of compound which primarily aid in the rapid disintegration of orally disintegrating 
tablets in the oral cavity. This class of disintegrants has been shown to be effective at excipient concentration as low as $2-10 \%$ [11]. Although the superdisintegrants primarily affect the rate of disintegration, when used at high levels it can also affect flowability of the powder, mouthfeel, tablet hardness, and friability [10]. One of the ways to overcome this problem is using a coprocessed superdisintegrants in orally disintegrating tablet formulation.

The widely used superdisintegrants are crospovidone, sodium starch glycolate, and croscarmellose sodium [12]. In the present investigation, the preparation and evaluation of atenolol orally disintegrating tablets using coprocessed superdisintegrants containing crospovidone and sodium starch glycolate were studied. The novelty of this study was the development of orally disintegrating tablets of atenolol using coprocessed crospovidone-sodium starch glycolate. Crospovidone was selected due to its high capillary activity, pronounced hydration capacity, and little tendency to form gels. Sodium starch glycolate was chosen due to its high swelling capacity. A combination of two types of superdisintegrants using coprocessed method can increase the flowability and compressibility of the powder mixture. Moreover, formulating orally disintegrating tablet using coprocessed superdisintegrants increase water uptake ratio with shortest wetting time and thereby decrease the disintegration time of the tablets by direct compression technique [8]. Ratio of crospovidone and sodium starch glycolate in coprocessed excipient influenced the physicochemical characteristics of orally disintegrating tablets. In this study, coprocessed superdisintegrants were prepared by three different ratios of crospovidone-sodium starch glycolate $(1: 1 ; 1: 2$; and $1: 3)$. The effect of different ratio of superdisintegrants has been evaluated to the pre-compression parameter and post-compression parameter of orally disintegrating tablets.

\section{MATERIALS AND METHODS}

\section{Materials}

Materials that were used in this study consists of atenolol p.g (Refarmed Chemicals, Lugano Switzerland), crospovidone (Kollidon ${ }^{\circledR}$ CL) p.g (BASF South East Asia Pre-Ltd), sodium starch glycolate p.g (Yung Zip Chemical IND.Co.LTD), magnesium stearate p.g (Faci Asia Pacific PTE LTD), aspartame f.g (Ajinomoto Co. Inc.), aqua demineralisata (Laboratorium of qualitative chemistry, University of Surabaya), mannitol DC p.g (Roquette Freres, Perancis), aerosil p.g (PT. Brataco), mint flavor f.g (KH Roberts), sodium dihydrogen fosfat p.a $\left(\mathrm{NaH}_{2} \mathrm{PO}_{4} \cdot 2 \mathrm{H}_{2} \mathrm{O}\right)$ p.a (Merck), disodium hydrogen fosfat p.a $\left(\mathrm{Na}_{2} \mathrm{HPO}_{4} \cdot 12 \mathrm{H}_{2} \mathrm{O}\right)$ p.a (Merck), natrium asetat trihidrat p.a. (Riedel), asam asetat glasial p.a (Merck), methanol pro HPLC (Mallinckrodt Chemicals), Avicel PH $102^{\circledR}$ p.g (Mingtai Chemical Co. LTD), talk (PT. Brataco), and Whatman filter paper no 41.

\section{Methods}

Preparation of co-processed superdisintegrants (crospovidonesodium starch glycolate)

The coprocessed superdisintegrants were prepared by solvent evaporation method [4]. Crospovidone and sodium starch glycolate (in the ratio of 1:1, $1: 2$, and 1:3) were blended in tumbling mixer. The powder then placed in beaker glass, and $50 \mathrm{ml}$ of ethanol were added to the powder. This mixture was mixed thoroughly and stirring using a magnetic stirrer for $2 \mathrm{~h}$. After stirring process, the mixture was placed in a water bath $\left(60^{\circ} \mathrm{C}\right.$ for $\left.2 \mathrm{~h}\right)$ until ethanol was evaporated. Wet granule mass was sieved through \#40 mesh, then wet granules were dried in a hot air oven at $60^{\circ} \mathrm{C}$ for $20 \mathrm{~min}$. The dried granules were sieved through \#40 mesh and stored in airtight container and protected from light for further use.

\section{Preparation of powder mixture}

Preparation of powder mixture of compression was performed by mixing the component in Table 1. Formula 1 using coprocessed crospovidonesodium starch glycolate (1:1), formula 2 using coprocessed crospovidonesodium starch glycolate (1:2), and formula 3 using coprocessed crospovidone-sodium starch glycolate (1:3). Atenolol and a half of Aerosil $200^{\circledR}$ mixed for 3 min using the tumbling mixer to decrease the electrostatic tendency of atenolol. This mixture then premixed with a portion of Avicel PH $102^{\circledR}$. After that, the mixture was mixed thoroughly with coprocessed crospovidone-sodium starch glycolate, Avicel PH $102^{\circledR}$, mannitol DC, aspartame, and mint flavor for $10 \mathrm{~min}$ in tumbling mixer. The powder mixture then was evaluated before compression (precompression test). After the pre-compression test, the powder mixture was mixed with talc, magnesium stearate, and Aerosil $200^{\circledR}$ for 3 min.

\section{Pre-compression evaluation}

Before compression, the powder mixture from each formula was evaluated by several parameters such as flowability, angle of repose, bulk density, tapped density, compressibility, Hausner ratio, and moisture content.

\section{Flowability and angle of repose}

Flowability and angle of repose were determined using the fixed funnel method. The powder mixture $( \pm 100 \mathrm{~g})$ was poured through a funnel that can be raised vertically to a maximum cone height (h) was obtained [4]. The radius of the heap (r) was measured, and the angle of repose $(\theta)$ was calculated using the formula:

$$
\tan \theta=\frac{h}{r}
$$

Time for the powder mixture to fall down through a funnel was used to calculate flowability of the powder.

\section{Bulk density}

Bulk density of powder mixture was determined by pouring the powder into a graduated cylinder. The bulk volume $(\mathrm{Vb})$ and weight of the blend $(\mathrm{m})$ were determined. The bulk density was calculated by this equation $[6,8]$.

$$
\text { Bulk density }=\frac{\mathrm{m}}{\mathrm{Vb}}
$$

Where,

$\mathrm{m}=$ Mass of powder mixture

$\mathrm{Vb}=$ Bulk volume of the powder

\section{Tapped density}

Tapped density of the powder mixture was determined using tapping machine. Tapped density is the ratio of the total mass of the powder (m) to the tapped volume of the powder (Vt). Volume was measured by tapping the powder for 500 times. The volume was read every 100 intervals $[6,8]$. Tapped volume was noted if the volume did not show a difference between two tapping intervals.

Tapped density $=\frac{\mathrm{m}}{\mathrm{Vt}}$

Where,

$\mathrm{m}=$ Mass of powder mixture

$\mathrm{Vt}=$ Tapped volume of the powder

\section{Compressibility}

Compressibility index is one of the methods to evaluate compressibility of the powder and flow property. Compressibility index can be calculated by comparing the bulk density $(\mathrm{Db})$ and tapped density (Dt) of the powder [13].

Compressibility index $=\frac{\mathrm{Dt}-\mathrm{Db}}{\mathrm{Dt}} \times 100$

Where,

Dt is the tapped density of the powder

$\mathrm{Db}$ is the bulk density of the powder 


\section{Hausner ratio}

Hausner ratio is an indirect index to predict powder flow $[4,13]$. Hausner ratio can be calculated by following formula:

Hausner ratio $=\frac{\mathrm{Dt}}{\mathrm{Db}}$

Where,

Dt is the tapped density of the powder

$\mathrm{Db}$ is the bulk density of the powder

Lower Hausner ratio $(<1.25)$ indicates better flow than the higher ones $(>1.25)$.

\section{Moisture content analysis}

The moisture content of the powder was set by analyzing around 5 grams of the powder. This evaluation was conducted using the moisture content analyzer. The moisture content of the powder can be calculated using this equation:

$\% \mathrm{MC}=\frac{\mathrm{w}-\mathrm{w}_{0}}{\mathrm{w}_{0}} \times 100 \%$

Where,

$\mathrm{w}$ is the weight of wet mass

$\mathrm{w}_{0}$ is the weight of dry mass

\section{Preparation of atenolol orally disintegrating tablets}

Orally disintegrating tablets of atenolol were prepared by direct compression method [5]. After pre-compression evaluation, the powder mixture was prepared for tableting process. Tableting process was conducted by compress the powder mixture using the Erweka ${ }^{\circledR}$ compression machine. The powder was compressed into $300 \mathrm{mg}$ tablet using $11 \mathrm{~mm}$ flat punches.

\section{Post-compression evaluation}

Evaluation was done to the atenolol orally disintegrating tablets of all formulations considering following parameters such as organoleptic, drug content uniformity, dimension, hardness, friability, wetting time, water absorption ratio, in vitro dispersion time, disintegration, and dissolution.

\section{Organoleptic}

Visual inspection was conducted to atenolol orally disintegrating tablets. Visual inspection consisted of color, shape, and taste of the tablets.

\section{Drug content uniformity}

The content uniformity test was carried out to ensure the homogeneity of atenolol in each tablet. Content uniformity of atenolol in orally disintegrating tablet was made out by sampling randomly 20 tablets from each formula, and then these tablets were weighed and triturated in a mortar. The powder equivalent to $25 \mathrm{mg}$ atenolol was weighed accurately and dissolved in $10 \mathrm{ml}$ methanol. The solution transferred to $100 \mathrm{ml}$ volumetric flask and a portion of acetate buffer $\mathrm{pH} 4.6$ was added. The solution was sonicated thoroughly, then acetate buffer $\mathrm{pH} 4.6$ was added to the volumetric flask until $100 \mathrm{ml}$. The undissolved matter was removed by filtration through Whatman No.41 filter paper. The filtrate was pipetted $10 \mathrm{ml}$ and diluted with acetate buffer $\mathrm{pH} 4.6$ and $25 \mathrm{ml}$ in a volumetric flask. This solution was assayed at $\lambda 274 \mathrm{~nm}$, using UV-Visible double beam spectrophotometer (Shimadzu UV-1800).

\section{Dimension}

Thickness and diameter of tablet were determined using vernier caliper. 10 tablets of each formula were determined its thickness and diameter to ensure uniformity of tablet size.

\section{Hardness}

The resistance of tablets to shipping, breakage, under conditions of storage, transportation, and handling before usage depends on its hardness [4]. For each formula, 10 tablets were determined its hardness using a Monsanto hardness tester. The tablet was held along its oblong axis in between the two jaws of the tester. At this point, reading should be zero $\mathrm{kg} / \mathrm{cm}^{2}$. Constant force was applied by rotating the knob until the tablet fractured. The value at this point was noted $[4,6]$.

\section{Friability}

Friability test was carried out to access the ability of the tablet to withstand abrasion in packaging, handling, and transport. Friability of atenolol orally disintegrating tablet was determined using Erweka rolling and impact durability tester. A sample of tablets equal to $6.5 \mathrm{~g}$ was weighed and placed in Erweka rolling and impact durability tester which revolves at a speed of $25 \mathrm{rpm}$ for $4 \mathrm{~min}$. The tablets were then dusted and reweighed. Percent weight loss (friability) was calculated using the following equation:

$\%$ Friability $=\frac{\mathrm{w}_{1}-\mathrm{w}_{2}}{\mathrm{w}_{1}} \times 100$

Where $\mathrm{w}_{1}$ was the weight of the tablet before test and $\mathrm{w}_{2}$ was the weight of the tablet after the test

\section{Wetting time}

Wetting time test was conducted to predict the time which is required to complete wetting atenolol orally disintegrating tablets. A piece of filter paper with $8 \mathrm{~cm}$ diameter was prepared on the Petri dish containing $10 \mathrm{ml}$ eosin solutions. Atenolol orally disintegrating tablet was placed carefully on the surface of filter paper. The time of eosin solution to cover the surface of the tablet was noted.

\section{Water absorption ratio}

A piece of filter paper was placed in a small Petri dish containing $10 \mathrm{ml}$ eosin solution. Atenolol orally disintegrating tablet was put on the paper and the time required for complete wetting was measured $[4,6]$. The wetted tablet was then weighed. Water absorption ratio (R) was determined using this equation:

$$
\mathrm{R}=\frac{\mathrm{w}_{\mathrm{a}}-\mathrm{w}_{\mathrm{b}}}{\mathrm{w}_{\mathrm{b}}} \times 100
$$

Where $\mathrm{W}_{\mathrm{b}}$ and $\mathrm{W}_{\mathrm{a}}$ were tablet weight before and after absorption.

\section{In vitro dispersion time}

One tablet was placed in a flask containing $6 \mathrm{ml}$ phosphate buffer $\mathrm{pH} 6.8$ with temperature $37 \pm 0.5^{\circ} \mathrm{C}$. The time required for complete dispersion was determined.

\section{Disintegration time}

Disintegration of atenolol orally disintegrating tablets was conducted using Hanson and Research disintegration tester. The distilled water at $37 \pm 0.5^{\circ} \mathrm{C}$ was used as disintegration media in $900 \mathrm{ml}$ volume. Six tablets were randomly chosen, and each tablet was placed in the tube, then the basket rack was positioned in the media. The time for the complete disintegration of the tablet with no palpable mass replaced on the screen was measured in seconds.

\section{Dissolution study}

In vitro dissolution study was performed using USP Type II Apparatus (paddle type) at $50 \mathrm{rpm}$ for $120 \mathrm{~min}$. Acetate buffer $\mathrm{pH} 4.6$ was used as a dissolution medium which was maintained at $37 \pm 0.5^{\circ} \mathrm{C}$. Aliquot $(10 \mathrm{ml})$ was taken at specified time intervals $(0,1,2,3,4,5,10,15,20,25,30$, $45,60,75,90,105$, and $120 \mathrm{~min}$ ). An equal amount of fresh dissolution medium was replaced immediately following the withdrawal of the 
sample. The absorbance of the medium was analyzed using UV-visible, double beam spectrophotometer (Shimadzu UV-1800) at $\lambda 274 \mathrm{~nm}$. The atenolol concentration which was released to the media was calculated. The data presented is the average of 6 determinations. A dissolution profile for each formula was plotted, and dissolution parameters such as \%Q, TQ\%, AUC, and dissolution efficiency (ED) were determined.

\section{RESULTS AND DISCUSSION}

Preparation of co-processed superdisintegrants (crospovidonesodium starch glycolate)

Coprocessed superdisintegrants were prepared by the solvent evaporation method. Coprocessed superdisintegran was prepared using crospovidone-sodium starch glycolate in three different ratios (1;1; 1:2; and 1:3). The result of Fourier-transform infrared (FT-IR) study and differential scanning calorimetry (DSC) study showed that crospovidone and sodium starch glycolate which was utilized in this study meet the specifications [15]. The results of FT-IR and DSC analysis showed that there was no chemical change between these two superdisintegrants. The results revealed that there was only physical entanglement of crospovidone and sodium starch glycolate. This condition leads to synergism of these two superdisintegrants $[16,17]$.

\section{Preparation of powder mixture}

Three formulas of orally disintegrating tablets of atenolol have been prepared in this study. Powder mixture of orally disintegrating tablets of atenolol were prepared using three different compositions of coprocessed superdisintegrants (Table 1). Crospovidone was chosen as one of the components of coprocessed disintegrants because it swells very little, spongy in nature, so produce porous tablets, and act by capillary action. Sodium starch glycolate was also chosen because it swells in three dimensions $7-12$ folds in $<30 \mathrm{~s}$ [17]. A directly compressible vehicle such as microcrystalline cellulose (Avicel ${ }^{\circledR} \mathrm{PH} 102$ ) and mannitol were used as filler. Microcrystalline cellulose was used as filler due to its ability to act as dry binder. Microcrystalline cellulose can improve the compactibility or tabletability of the compression mix [18]. Mannitol was used as filler to enhance mouthfeel [19]. Mannitol also can improve patient compliance by imparting a cool sensation and sweet mild taste. Directly compressible mannitol can flow well, so that mannitol improves the flow properties of other materials [20]. Aspartame was used as a sweetener. It enhanced flavor systems and also used as a taste masking agent. The sweetening power of aspartame is approximately 180-200 times to sucrose [20]. Mint flavor was used as a flavoring agent. It can enhance the characteristics, taste, and odor of atenolol orally disintegrating tablets. Magnesium stearate was used as a lubricant, Aerosi ${ }^{\circledR} 200$ was used as glidant, and talc was used as antiadherent.

\section{Pre-compression evaluation}

The results of pre-compression evaluation of atenolol orally disintegrating tablet can be seen in Table 2 .

Based on the results of pre-compression parameter, it can be concluded that all formulas (formula 1, formula 2, and formula 3) have good flow velocity. All formulas have flow velocity between 4 and $10 \mathrm{~g} / \mathrm{s}$, indicating good flow velocity for direct compression [12]. The flow velocity of the powder blend is essential to predict the ability of powder blend to fulfill the dies during compression stage. The homogeneity of powder flow will produce a low variation of tablet weight $[12,13]$. Angle of repose has been used to characterize the flow properties of powders.

Angle of repose is a characteristic related to interparticle friction or resistance to movement between particles. The results of angle of repose showed that all formulas exhibited excellent flow properties, because the value of angle of repose was $25^{\circ}-30^{\circ}$ [15]. The compressibility index and Hausner ratio have become the simple, fast, ad popular methods to predict powder flow characteristic and compressibility characteristic. Powder blends of formula 1 categorized as poor flow and compressibility character, moreover, formula 2 and formula 3 can be categorized as passable material for direct compression [15]. Powder blends of formula 1 consist of high fines proportion so that the flow characteristic was poor. Moisture content of powder blend was an essential parameter for direct compression. There was a limitation when the powder blend contains high moisture content. The high moisture content in a powder blend causes the probability of picking during the compression stage become higher. Based on the results in Table 1, it can be seen that the higher sodium starch glycolate proportion in coprocessed superdisintegrants cause the higher moisture content of powder blend. This condition occurred due to sodium starch glycolate is a hygroscopic material [21]. Relative humidity of production room must be controlled during production to obtain desired tablet characteristics. Overall, the results of pre-compression parameter showed that the powder blend was suitable to be developed using direct compression method.

\section{Post-compression evaluation}

The compressed tablets were evaluated for physicochemical parameters and dissolution. The results of pre-compression evaluation are tabulated in Table 3

Atenolol orally disintegrating tablets were produced in this study were white, round shape, no odor, sweet, and mint flavor. Drug content of all formulations was observed between $99.48 \pm 0.13 \%$ and $99.96 \pm 0.51 \%$. Drug content in all formulas met the specification of atenolol content which has been stated in compendia (90.0-110.0\%) [15]. Drug content for all formulations showed that the ability of the powder to flow and fulfill the die were uniform [14]. Consequently, this condition caused the uniformity of drug distribution into the tablets. The values of thickness and diameter of the tablet showed uniformity in die fill, good flow properties, and good powder compressibility. All the formulas produce appropriate thickness and diameter dimension of the tablets (Fig. 1).

Wetting time test is not standard USP test, but it is useful for quality control and provides a correlative evaluation to water uptake rates. Unlike the disintegration test, the wetting test uses minimal water, which is representative of the quantity of moisture available in the oral cavity [11]. The wetting time for all the formulated tablets was in the range of $6.67 \pm 0.58-7.67 \pm 0.58 \mathrm{~s}$. The faster wetting time of the tablets produces better disintegration time. The results of wetting time

Table 1: Formula of atenolol orally disintegrating tablet using coprocessed crospovidone-sodium starch glycolate

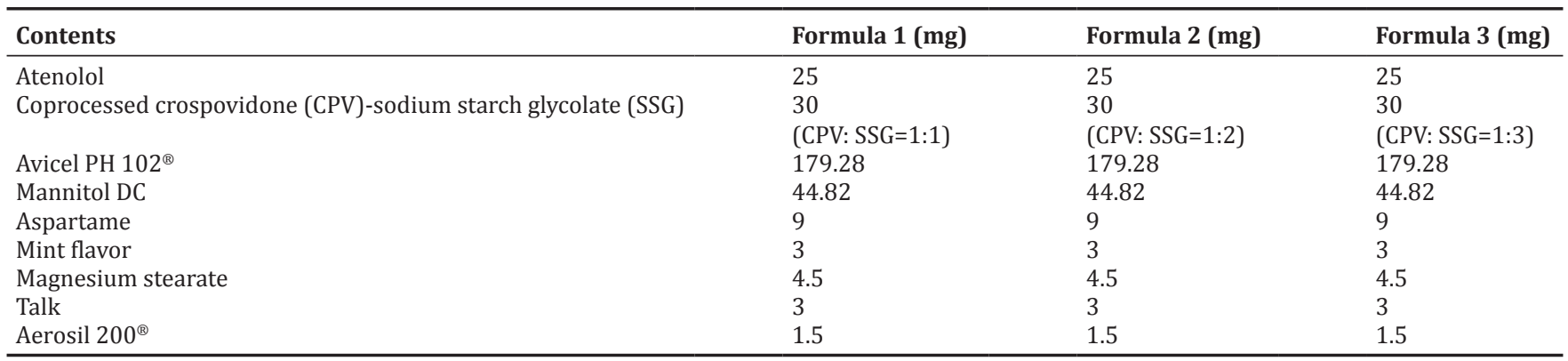


showed that atenolol orally disintegrating tablets which were produced in this study have fast wetting time. Moreover, there was no significant difference ( $p>0.05$ ) of wetting time between formula 1 , formula 2 , and formula 3 . The water absorption ratio test was conducted to predict the amount of water which can be absorbed by orally disintegrating tablets. The higher water absorption ratio describes the higher water which can be trapped in the structure of the tablets. This phenomenon indicates that the amount of water to cause disintegration was higher in the tablets which have a high water absorption ratio. Water absorption ratio of three formulas was founded in the range $237.83 \pm 14.55 \%$ $273.50 \pm 19.43 \%$. Orally disintegrating tablets which have lower water absorption ratio were more preferable to develop. Water absorption ratio of three formulas was more than $100 \%$. This was due to the characteristics of sodium starch glycolate which absorbed water until 200-300 [23,24]. It was observed form the previous study that the disintegration process started by wetting of the tablets [25]. Moreover, wetting time test was necessary to be conducted in the orally disintegrating tablets evaluation. Based on the results of statistical

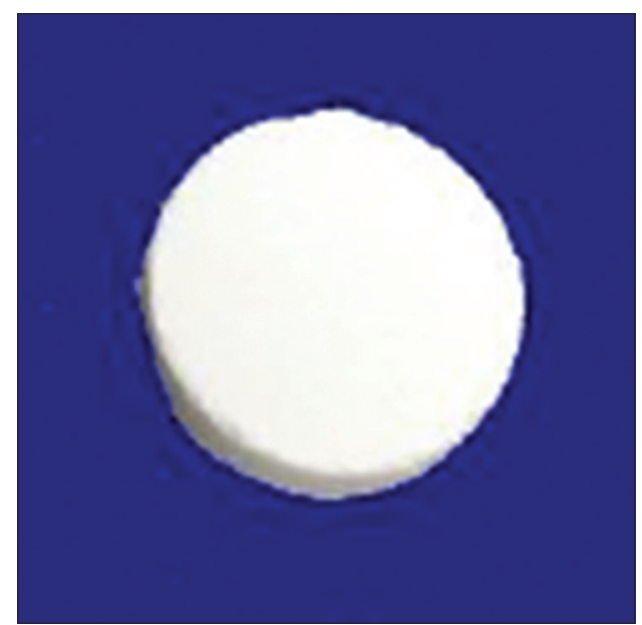

Fig. 1: Atenolol orally disintegrating tablet

Table 2: The results of pre-compression evaluation of powder blend (formula 1, formula 2 , and formula 3 )

\begin{tabular}{llll}
\hline Parameters & \multicolumn{3}{l}{ Formulation code } \\
\cline { 2 - 4 } & Formula 1 & Formula 2 & Formula 3 \\
\hline Flow velocity (g/s) & $6.32 \pm 0.07$ & $5.56 \pm 0.00$ & $5.56 \pm 0.00$ \\
Angle of repose ( $\left.{ }^{\circ}\right)$ & $29.25 \pm 0.00$ & $27.39 \pm 0.62$ & $25.74 \pm 0.78$ \\
Carr's index (\%) & $29.15 \pm 0.22$ & $25.11 \pm 0.48$ & $23.28 \pm 0.50$ \\
Hausner's ratio & $1.412 \pm 0.005$ & $1.335 \pm 0.009$ & $1.304 \pm 0.008$ \\
Moisture content (\%) & $5.89 \pm 0.13$ & $6.00 \pm 0.10$ & $6.19 \pm 0.19$ \\
\hline
\end{tabular}

analysis, it can be concluded that there was no significant difference of water absorption ratio among all formulas $(p>0.05)$.

Disintegration study showed that all formulas fulfill the specification which has been stated in compendia $(<1 \mathrm{~min})$ [7]. There was a significant difference of disintegration time between three formulas. The increased of sodium starch glycolate proportion in coprocessed superdisintegrants crospovidone-sodium starch glycolate, caused the disintegration time of the tablets became slower. Each superdisintegrants has a different characteristic in terms of wicking and disintegration. Crospovidone is a cross-linked homopolymer of $\mathrm{N}$-vinyl-2-pyrollidone which has good water wicking characteristics and smaller disintegration times due to hydrophilic pores created in compression [11,22]. Contrary, sodium starch glycolate at high concentrations has tendered to coagulate and swell in the presence of water. This condition can create a wicking barrier and reduce the disintegration times of atenolol orally disintegrating tablet $[11,12]$. In vitro dispersion time test was conducted to predict the ability of orally disintegrating tablets to disintegrate in small volumes of saliva $( \pm 6 \mathrm{ml})$. This test condition described the factual condition in the oral cavity. In vitro dispersion study explained that there was a significant difference of in vitro dispersion time between formula 1 and formula 2 $(p<0.05)$, also formula 1 and formula $3(p<0.05)$. There was a decrease of in vitro dispersion time with successive increases of sodium starch glycolate concentration in coprocessed superdisintegrants. Formula 1 had the lowest in vitro dispersion time $(23.67 \pm 3.21 \mathrm{~s})$. Based on this fact, it can be concluded that formula 1 dispersed in the mouth quickly and released the drug early as compared to other formulas [6].

The tablet must have good integrity and mechanical resistance during production and distribution process. Hardness test was carried out with all formulas, and the results showed suitable hardness for orally disintegrating tablets. The hardness of atenolol orally disintegrating tablets was found to be in the range of $2.40-3.50 \mathrm{~kg}$. The specification of tablet hardness in orally disintegrating tablets is $2.0-4.0 \mathrm{~kg}[6,12]$. The results of friability and abrasion test revealed that atenolol orally disintegrating tablets which have been made in this study was within $1 \%$, and was in the range of $0.20-0.44 \%$. These results indicate that all formulations have good physical strength and can withstand the mechanical shocks which can be observed during handling, shipping, and transportation [19].

In vitro dissolution study was conducted in a USP apparatus 2, paddle method using acetate buffer $\mathrm{pH} 4.6$ as dissolution medium. Paddle speed was maintained at $50 \mathrm{rpm}$ during this study. Samples were collected at predetermined time intervals and replaced with an equal volume of fresh medium. The collected samples, then analyzed using UV-VIS spectrophotometer. The dissolution profile of atenolol orally disintegrating tablet formula 1 , formula 2 , and formula 3 can be seen in Fig. 2. Based on this dissolution profile, several dissolution parameters can be calculated. The results of dissolution parameters are shown in

Table 3: The results of post-compression evaluation of atenolol orally disintegrating tablets (formula 1, formula 2 , and formula 3 )

\begin{tabular}{llll}
\hline Parameter & Formula & & Formula 3 \\
\cline { 2 - 4 } & Formula 1 & Formula 2 & White, round shape, no odor, \\
\hline Organoleptic & White, round shape, no odor, & White, round shape, no odor, & sweet, and mint flavor \\
& sweet, and mint flavor & sweet, and mint flavor & $99.96 \pm 0.51$ \\
Assay (\%) & $99.48 \pm 0.13$ & $99.48 \pm 0.51$ & $11.10 \pm 0.00$ \\
Diameter (mm) & $11.10 \pm 0.00$ & $11.10 \pm 0.00$ & $3.80 \pm 0.10$ \\
Thickness (mm) & $4.0 \pm 0.10$ & $3.80 \pm 0.10$ & $7.67 \pm 0.58$ \\
Wetting time (s) & $6.67 \pm 0.58$ & $7.00 \pm 0.00$ & $273.50 \pm 19.43$ \\
Water absorption ratio (s) & $237.83 \pm 14.55$ & $258.75 \pm 3.98$ & $2.40 \pm 0.46$ \\
Hardness (kg) & $3.50 \pm 15.06$ & $2.15 \pm 11.23$ & $7.00 \pm 0.00$ \\
Disintegration time (s) & $6.00 \pm 0.00$ & $7.00 \pm 0.00$ & $55.00 \pm 3.60$ \\
Dispersion time (s) & $23.67 \pm 3.21$ & $54.30 \pm 4.04$ & $0.25 \pm 0.09$ \\
Friability (\%) & $0.25 \pm 0.09$ & $0.20 \pm 0.09$ & $0.40 \pm 0.17$ \\
Abrasion (\%) & $0.25 \pm 0.09$ & $0.44 \pm 0.15$ & \\
\hline
\end{tabular}


Table 4: Dissolution parameters of atenolol orally disintegrating tablet formula 1 , formula 2 , and formula 3

\begin{tabular}{lllll}
\hline Formula & TQ\% (min) & \% Q & AUC (\% m) & ED \\
\hline Formula 1 & $1.70 \pm 0.01$ & $92.75 \pm 0.00$ & $11149.13 \pm 13.15$ & $92.91 \pm 0.11$ \\
Formula 2 & $1.93 \pm 0.04$ & $93.27 \pm 0.64$ & $11023.51 \pm 9.62$ & $91.87 \pm 0.08$ \\
Formula 3 & $1.69 \pm 0.05$ & $91.85 \pm 1.70$ & $11001.11 \pm 1.04$ & $91.68 \pm 0.01$ \\
\hline
\end{tabular}

ED: Dissolution efficiency, AUC: Area under curve

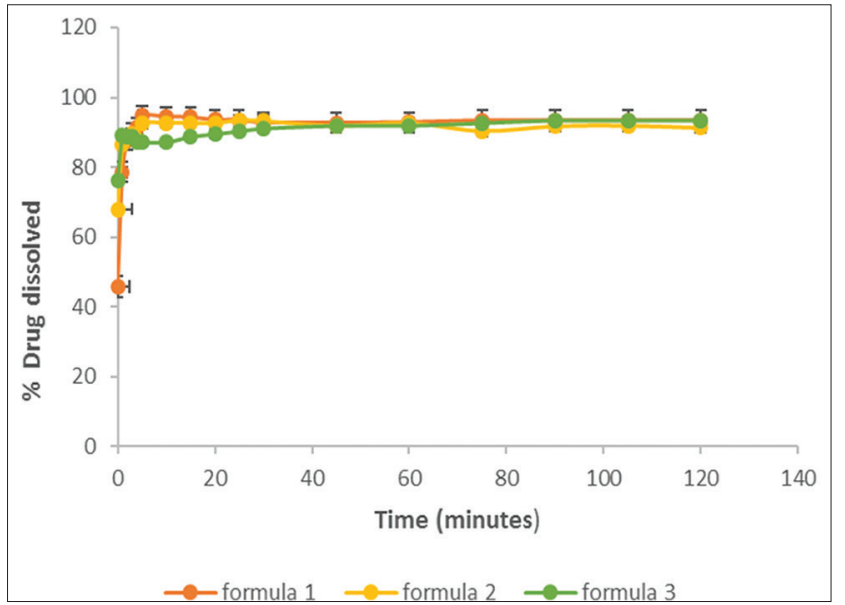

Fig. 2: Dissolution profile of atenolol orally disintegrating tablet formula 1 , formula 2 , and formula 3 formula 1 , formula 2 , and formula 3

Table 4. The dissolution parameters consist of specified time for drug dissolved (TQ\%), the amount of the drug dissolved in a specified time interval (\%Q), area under curve (AUC), and ED. Dissolution requirement of atenolol tablets in the $1^{\text {st }}$ stage (S1) is more than $85 \%$ of atenolol must be dissolved in the dissolution medium at $30 \mathrm{~min}$. All formulas that have been carried out in this study meet the specification.

There was a significant difference of AUC value and ED among all formulas $(p<0.05)$. The results showed that formula 1 had the highest AUC value and ED. Dissolution efficiency of formula 1 folded 1.01 compared to formula 2 and formula 3 . The increased of sodium starch glycolate proportion in coprocessed superdisintegrants caused inhibition of atenolol release from orally disintegrating tablets. The higher proportion of sodium starch glycolate in orally disintegrating tablets can produce a thick gel layer so that the release of the drugs from the tablets will be inhibited.

The dissolution profiles of orally disintegrating tablets of atenolol using coprocessed crospovidone-sodium starch glycolate showed better dissolution compare to the dissolution profile of orally disintegrating tablets of atenolol using single component of superdisintegrants. TQ\% of orally disintegrating tablets of atenolol which are using single component of superdisintegrant were $12 \mathrm{~min}$, moreover, TQ\% of orally disintegrating tablets of atenolol from this formulation were approximately 1.69-1.93 min [6]. Based on post-compression data, it can be revealed that there was an inverse correlation between disintegration time and ED ( $r>0.9)$. The faster disintegration time produced high ED of atenolol. It was due to the onset of dissolution occurred faster in the tablets which had faster disintegration time. In this study, the mechanism of tablet disintegration was influenced by the characteristics of coprocessed superdisintegrants. Such a difference characteristics of superdisintegrants can affect drug dissolution [25]. Coprocessed superdisintegrants rapidly deformed, which leads to the breakdown of the tablet [26]. In addition, water in the hydrophilic pores may also help to break hydrogen bonds present between starch grains and produced heat, both of which may aid in disintegration $[11,12]$.
Coprocessed mixture played an important role in decreasing disintegration time and enhanced the drug release [27].

\section{CONCLUSION}

The results from this study showed that coprocessed superdisintegrants (crospovidone-sodium starch glycolate) ratio affect the physicochemical characteristics of atenolol orally disintegrating tablet. Based on precompression evaluation and post-compression evaluation, formula 1 which using coprocessed was the best formula. Formula 1 showed the fastest wetting time $(6.67 \pm 0.58 \mathrm{~s})$, disintegration time $(6.00 \pm 0.00 \mathrm{~s})$, and in vitro dispersion time $(23.67 \pm 3.21 \mathrm{~s})$ among all formulas. The faster disintegration time of atenolol orally disintegrating tablets from formula 1 caused a significant impact in dissolution characteristics. Onset of dissolution of formula 1 became faster compared to formula 2 and formula 3. Moreover, ED of formula $1(92.91 \pm 0.11)$ was higher than formula 2 and formula 3 . Based on these facts, it can be concluded that coprocessed superdisintegrants of crospovidone-sodium starch glycolate (1:1) were the best composition to produce atenolol orally disintegrating tablets with desired physicochemical characteristics.

\section{ACKNOWLEDGMENTS}

The authors are thankful to KEMENRISTEK DIKTI, Indonesia, for providing research grants in 2017 (No. 24/SP-Lit/LPPM-01/Dikti) $\mathrm{FF} / \mathrm{V} / 2017$ ) to execute this research

\section{AUTHORS CONTRIBUTION}

Guidance for the work, dissolution study, data interpretation and corrections, and writing of the manuscript were done by first author Nani Parfati. Experimental design of formulation, consideration of manufacturing process parameter, physicochemical analysis and characterization, and writing of the manuscript were done by second author Karina Citra Rani. Experimental working, data generation, and reporting of data summary were done by Meilany.

\section{CONFLICT OF INTERESTS}

There is no conflict of interests

\section{REFERENCES}

1. Dipiro JT, Talbert RL, Yee GC, Matzke GR, Wells BG, Posey LM. Pharmacotherapy: A Pathophysiologic Approach. $7^{\text {th }}$ ed. New York: McGraw-Hill; 2008.

2. Khirwadkar P, Dashora K. Formulation and evaluation of fast dissolving tablets Atenolol. J Chem Pharm Sci 2013;6 Suppl 2:113-9.

3. Sweetman. Martindale the Complete Drug Reference. $36^{\text {th }}$ ed. London: Pharmaceutical Press; 2009.

4. Kumare MM, Marathe RP, Kawade RM, Ghante MH, Shendarkar RR. Design of fast dissolving tablet of atenolol using novel co-processed super disintegrants. Asian J Pharm Clin Res 2013;6 Suppl 3:81-5.

5. Fu Y, Yang S, Jeong SH, Kimura S, Park K. Orally fast disintegrating tablets: Developments, technologies, taste-masking and clinical studies. Crit Rev Ther Drug Carrier Syst 2004;21:433-76.

6. Chandrasekhar P, Shahid MS, Niranjan BM. Formulation and evaluation of oral dispersible tablets of anti hypertensive drug atenolol. Int J Pharm 2013;3 Suppl 2:79-84.

7. US Department of Health and Human Services Food and Drug Administration Center for Drug Evaluation and Research. Guidance for Industry: Orally Disintegrating Tablets. New Hampsire Eve: Division of Drug Information Food and Drug Administration; 2008.

8. Shirshand SB, Ramani RG, Swamy PV. Novel co-processed super disintegrants in the design of fast dissolving tablets. Int J Pharm BioSci 2010;1:1-11.

9. Kapse NK, Bharti VP, Birajdar AS, MundeAV, Panchal PP. Co-processed super disintegrants: Novel technique for design orodispersible tablets. J Innov Pharm Biol Sci 2015;2 Suppl 4:541-55.

10. Prateek P, Pramod S, Shiv G, Ajay P. Co-processed super disintegrants a novel approach for reducing risk in dosage form formulation. $\mathrm{J}$ Med Pharm Allied Sci 2014;3:45-54.

11. Mittapalli RK, Qhattal HS, Lockman PR, Yamsani MR. Varying 
efficacy of superdisintegrants in orally disintegrating tablets among different manufacturers. Pharmazie 2010;65:805-10.

12. Hahm HA, Augsburger LL. Orally disintegrating tablets and related tablet formulations. In: Pharmaceutical Dosage Forms: Tablets. New York: Informa Healthhcare; 2008. p. 293-312.

13. Aulton M, Summers M. In: Aulton's Pharmaceutics the Design and Manufacture of Medicines. Philadelphia, PA: Churchill Livingstone; 2013. p. 187-99.

14. Lachman L, Lieberman H, Kanig JL. Drying. In: Pharmaceutical Dosage Forms Tablet. Vol. 2. New York: Marcel Dekker; 1991. p. 4764.

15. United States Pharmacopeial Convention. United States Pharmacopeia 40 National Formulary 35. Rockville: United States Pharmacopeial Committee; 2017. p. 2886-8.

16. Savitra D, Dimesh M. Design and assessment of losartan potassium oro-dispersible tablets using modernistic versatile co-processed superdisintegrants. Int J Pharm Pharm Res 2016;7:424-36.

17. Bhowmik D, Chiranjib B, Krishnakanth HS, Pankaj KM, Margret C. Fast dissolving tablet: An overview. J Chem Pharm Res 2009;1:163-77.

18. Thoorens G, Krier F, Leclercq B, Carlin B, Evrard B. Microcrystalline cellulose, a direct compression binder in a quality by design environment - A review. Int J Pharm 2014;473:64-72.

19. Nagendrakumar D, Raju SA, Shirsand SB, Para MS. Design of fast dissolving granisetron HCL tablets using novel co-processed superdisntegrants. Int J Pharm Sci Rev Res 2010;12:58-62.

20. Shankarrao KA, Mahadeo GD, Balavantrao KP. Formulation and in vitro evaluation of orally disintegrating tablets of olanzapine-2-hydroxypropyl$\beta$-cyclodextrin inclusion complex. Iran J Pharm Res 2010;9:335-47.

21. Rowe RC, Paul JS, Sian CO. Handbook of Pharmaceutical Excipients. $6^{\text {th }}$ ed. Washington DC: Pharmaceutical Press; 2009. p. 45, 404, 424.

22. Kornblum SS, Stoopak SB. A new tablet disintegrating agent: Crosslinked polyvinylpyrrolidone. J Pharm Sci 1973;62:43-9.

23. Panigrahi R, Behera S, Panda C. A review on fast dissolving tablets. Webmed Central Pharm Sci 2010;1:1-15.

24. Mahendrakumar P, Liew CV, Heng PW. Review of disintegrants and disintegration phenomena. J Pharm Sci 2016;105:2545-55.

25. Mohapatra S, Pattanaik P, Sudam C. Role of superdisintegrants for in vitro characterization of loratadine orodispersible tablets. Int J Pharm Pharm Sci 2012;4:319-23.

26. Waigh MP, Yewale CP, Zate SU, Kothawade PI, Mahale GH. Formulation and evaluation of fast dispersible tablets of aceclofenac using different superdisintegrant. Int J Pharm Pharm Sci 2010;2:154-7.

27. Preethi GB, Banerjee S, Shivakumar HN, Kumar MR. Formulation of fast-dissolving tablets of doxazosin mesylate drug by direct compression method. Int J Appl Pharm 2017;9:22-8. 